\section{Spectral Dependence of Laser Light on Light- tissue Interactions and its Influence on Laser Therapy: An Experimental Study}

\section{Abstract}

This paper aimed to summarize available facts about the spectral influence on reflection, refraction and absorption and to measure relative absorption of different wavelengths. The experiment showed that longer wavelengths lead to decreasing energy absorption and refraction index in the melanin, as well as a reduction of hemoglobin energy absorption. Longer wavelengths increase the probability of the interaction with water particles and its own light absorption. We conclude that reflection and melanin absorption are negligible for wavelengths higher than $1000 \mathrm{~nm}$ due to the ability to penetrate higher amounts of energy into the tissue. Additionally, water absorption increases with the longer wavelengths and refraction index and hemoglobin absorption are reduced.

Keywords: Laser light tissue interaction; Wavelength; Laser

\section{Marshall RP1* and Vlková K² \\ RasenBallsport Leipzig GmbH, Cottaweg 3, D-04177 Leipzig, Germany \\ 2 Faculty of Biomedical Engineering, Czech Technical University in Prague, Prague, The Czech Republic}

\section{*Corresponding author: \\ Dr. Robert Percy Marshall}

\section{Robert.Marshall@redbulls.com}

RasenBallsport Leipzig GmbH, Cottaweg 3, D - 04177 Leipzig, Germany.

Tel: +49 1795399606

Citation: Marshall RP, VIková K (2020) Spectral Dependence of Laser Light on Light-tissue Interactions and its Influence on Laser Therapy: An Experimental Study. Insights Biomed Vol.5 No.1:1

\section{Introduction}

Laser light is characterized as coherent, polarized and monochromatic electromagnetic waves [1]. Research provides information on its usage in medicine for both invasive and noninvasive purposes [2]. Laser therapy is a non-invasive application which transfers energy deep into the tissue using wavelengths that range between $400 \mathrm{~nm}$ to $1064 \mathrm{~nm}$ [3]. Effects of laser therapy include pain relief which is caused by the water absorption of the light and biostimulation induced by the cell energy absorption. Efficacy of the non-invasive application of laser to the tissues depends on photon propagation and fluence rate distribution within irradiated tissues which can be affected by its wavelength [4]. Effects of laser therapy using different wavelengths have been the subject of previous investigations [512]. Furthermore, studies only investigated the medical effects of the laser light on specific wavelengths. Comparable reviews on how specific wavelengths of light can affect the efficacy of the therapy are still missing. The main purpose of this study was to to summarize basic interactions between human tissue and laser, optical properties of human tissue and effects of laser light wavelength.

\section{Research Methodology}

\section{Literature research}

A computerized search of online scientific databases Pubmed, MEDLINE, Springer, Libertpub, Wiley and NCBI was conducted in the period January-April 2019. The review was limited to literature published in English. There was no limitation for publication year. Articles were defined to be relevant for this review if their key words covered the interaction between laser light and human tissue. Furthermore, all articles were selected according to the wavelength of the studied light. Range of interest was defined from $400 \mathrm{~nm}$ to $1064 \mathrm{~nm}$ which are typical wavelengths used in laser therapy.

\section{Experimental apparatus}

The experiment used various samples of optical phantoms with the thickness of 1,3 and 5 centimeters [13]. Relative energy density was calculated using approximation of the measured values. Laser radiation was emitted from two different devices with the individual wavelengths of $1064 \mathrm{~nm}$, and combined wavelengths of $810 \mathrm{~nm}$ and $970 \mathrm{~nm}$. Low pass filter for $950 \mathrm{~nm}$ was used for the measurement of $810 \mathrm{~nm}$ wavelength. Power was measured by the L40 (TSB01-005) + Vega (TSA01-011) power meter. Measured beam size was common for all measurements to $10 \mathrm{~mm}$ in diameter.

\section{Results}

\section{Literature research part}

Interactions between laser light and human tissue: Light is 
composed of photons and is characterized by wavelength, which represents the frequency of the electromagnetic waves. Laser light is monochromatic, polarized and coherent energy. Monochromaticity refers energy being used to produce light on only one wavelength, whereas polychromatic light refers to energy that is comprised of more than one wavelength. Stimulating the atoms of the individual material can be achieved by laser light using a defined wavelength. Therefore, the wavelength is directly related to the active medium $[14,15]$

Light-skin interactions: Human skin is the biological border for the internal structures of the human body. It serves as a mechanical, chemical and optical protection.

Reflection: Reflection is defined as the loss of electromagnetic radiation caused by the difference in the refractive index between the two indices of refraction [16]. Regular reflectance of human skin is between $4 \%$ and $7 \%$ [17]. Numerical model calculations of transmittance and remittance of the dermal skin section shows decreasing reflection in correlation with higher wavelengths. Decreasing spectral reflectance was shown in measurements which was observed on the human dermis layer $[18,19]$. Measurement confirms that wavelengths in near-infrared (NIR) (above $1000 \mathrm{~nm}$ ) lead to less energy loss. The ratio of reflected and transmitted energy decreases [20]. Laser light which is not reflected or absorbed in the medium travels into the deep lying structures.

Refraction (Scattering): Refraction refers to deflection of light beams from a straight trajectory caused by microscopic nonuniformities within the medium. The type of light scattering depends on the size of the interaction particles and the wavelength of incoming light [21]. According to the wavelength of the scattered light, it can be divided into elastic, without loss of energy, or inelastic refraction [22]. The decreasing trend of the scattering index was calculated from measurements of spectral remittance and transmittance of thin dermal sections under conditions appropriate to the application of Kubelka-Munk's theory of radiation transfer [19]. This scattering behavior was also mimicked by the mathematical expression which results to the value $1.5 \mathrm{~cm}^{-1}$ for $1064 \mathrm{~nm}$ wavelength, which is the minimum value, compared to the $2.16 \mathrm{~cm}^{-1}$ for $980 \mathrm{~nm}$ and $4.6 \mathrm{~cm}^{-1}$ for $810 \mathrm{~nm}$. Decreasing dependency of the wavelength refractive index for different types of human soft tissue was observed [23]. A decrease of refraction index with a longer wavelength was confirmed in previously conducted studies [24,25].

Absorption: Absorption is the process of transferring energy from light to the target substance which results in energy loss and is defined by the absorption coefficient [26]. The main human tissue absorbers of laser light are melanin, hemoglobin and water.

Absorption in melanin: Melanin is a neutral light-absorbing chromophore with a broad absorbing spectra [27,28]. Melanin can be found in the epidermis by approx. $3 \%$ for Caucasians, up to $16 \%$ for Mediterraneans and $43 \%$ for highly pigmented Africans [27]. The energy absorption while passing the epidermis is mostly caused by melanin. Based on this information, absorption of the light increases with the concentration of melanin in the skin. Spectral absorption is the main subject matter of the several studies reviewed. Furthermore, in NIR regions the absorption of melanin's peak is between $300 \mathrm{~nm}$ and $400 \mathrm{~nm}$ and decreases for longer wavelengths [29-34]. In wavelengths beyond 1100 $\mathrm{nm}$, absorption of melanin is nearly negligible [19]. Melanin absorption can differ individually. Generally based on the mathematical expression from various published studies the threshold exposure for explosive vaporization of melanosomes melanin absorption index for 1064 is $55 \mathrm{~cm}^{-1}$ compared to $72 \mathrm{~cm}^{-1}$ for $980 \mathrm{~nm}, 136 \mathrm{~cm}^{-1}$ for $810 \mathrm{~nm}$ and $228 \mathrm{~cm}^{-1}$ for $690 \mathrm{~nm}$ [32]. Results for the whole spectrum are shown in Figure 1.

Absorption in water: Water is a weak absorbing chromophore in the visible wavelength spectrum but its absorption increases within the NIR and infrared (IR) regions. Water is one of the most prevalent molecules which can be found throughout the whole body, including intracellular and extracellular fluid, plasma and blood $[35,36]$. Studies shows that water absorption is almost non-existent below $800 \mathrm{~nm}$, the water maximal absorption index for the range $700 \mathrm{~nm}-900 \mathrm{~nm}$ was 0.026 compared to the range $900 \mathrm{~nm}-1150 \mathrm{~nm}$ which had 0.46 [37-39].

Absorption in hemoglobin: Hemoglobin is the main blood component responsible for absorbing and scattering radiation. Actual absorption spectra depends on the state of the hemoglobin, which could be either oxygen rich or poor. The main difference between these two states occurs at wavelengths over $950 \mathrm{~nm}$ [40]. According to Tseng et al. absorption of the deoxyhemoglobin decreases continuously from the wavelength value of $900 \mathrm{~nm}$ [39]. Both of the hemoglobin states have maximal peaks of absorption in the near infrared range at wavelengths of $600 \mathrm{~nm}$. Spectral absorption coefficients for the range $650 \mathrm{~nm}$ $1042 \mathrm{~nm}$ were measured and can be approximated to the range $1200 \mathrm{~nm}$ [41]. Results for the specific wavelengths are shown in the Table 1.

\section{Experimental part}

Relative absorption of the energy was measured for wavelengths.

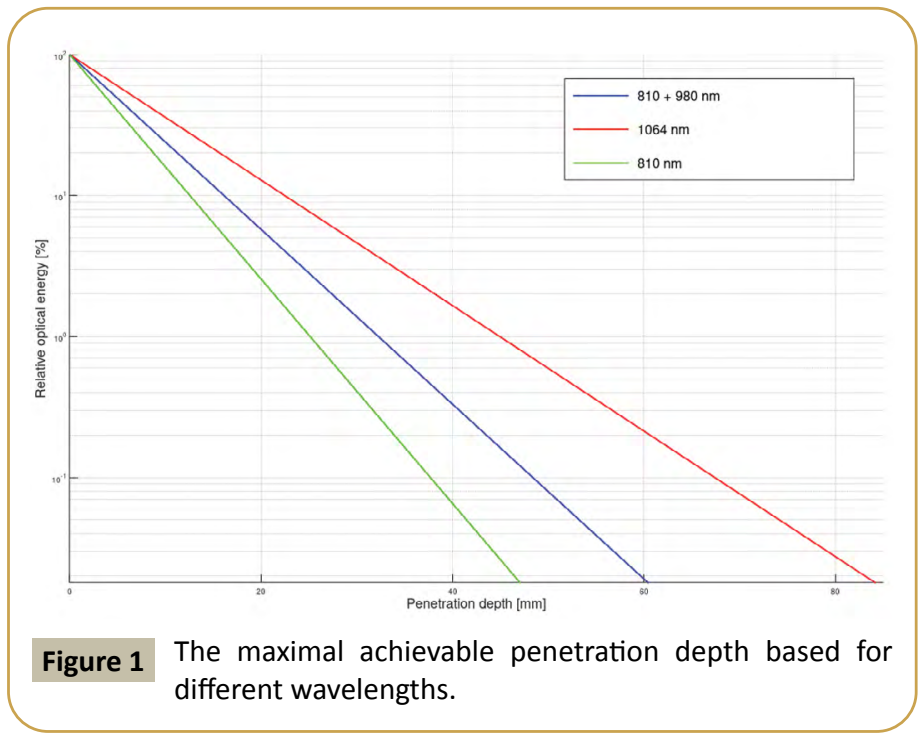


Main percentual difference was observed on the sample layer of $6.17 \mathrm{~mm}$ thickness where $47 \%$ was measured for $1064 \mathrm{~nm}$ compared to the $25 \%$ for the $810 \mathrm{~nm}$. Minimal difference was measured for the $0.25 \mathrm{~mm}$ sample. All measured values are in Table 2.

All measured values were used for the mathematical approximation to conclude the maximal achievable penetration depth based on the relative absorption of the energy. For the 810 $\mathrm{nm}$ wavelength less than $0.001 \%$ of the power pass to the depth beyond $4.8 \mathrm{~cm}$. For the $1064 \mathrm{~nm}$ wavelength the power limit of $0.001 \%$ can be found in the depth of $8.1 \mathrm{~cm}$.

\section{Discussion}

This paper summarizes the interaction of laser light with human tissue and its spectral dependence. Laser light transmission and penetration depends on the structure of the targeted tissue, its optical properties and wavelengths. Decreasing reflection index allows a higher amount of the light that resembles the infrared range to penetrate the human tissue, specifically for the wavelengths above $1000 \mathrm{~nm}[19,20]$. Penetrated light is split by the refraction with the tissue particles into the different directions and decrease the total energy. Probability of the interaction between the light and the particle depends on the size of the particle and light wavelength. Moreover, wavelengths with a shorter wavelength interact with smaller particles which lead to power loss. Decreasing tendency of the refraction index was observed and measured on the different types of the human tissue $[21,22]$. Spectral dependency of the refraction index was calculated and results show a three times higher refraction index for $810 \mathrm{~nm}$ than for $1064 \mathrm{~nm}$. Targeted process of the medical application of laser light is its absorption which converts the light into different types of energy. Absorption is affected by the individual tissue particles which mainly are melanin, hemoglobin and water. Melanin is contained within the epidermis by up to $43 \%$ and increases light absorption on the skin. Maximal absorption index was placed in the range of $300 \mathrm{~nm}$ and $400 \mathrm{~nm}$ [27-34]. However, the difference between wavelengths from $690 \mathrm{~nm}$ to $1064 \mathrm{~nm}$ was measured and the results confirm the decreasing tendency of the absorption coefficient from 228 $\mathrm{cm}^{-1}$ for $690 \mathrm{~nm}$ to $55 \mathrm{~cm}^{-1}$ for $1064 \mathrm{~nm}$ [32]. For wavelengths beyond $1100 \mathrm{~nm}$ it is essentially negligible [35]. Water is one of the most prevalent molecules which can be found throughout the whole body with negligible absorption index for wavelengths below $800 \mathrm{~nm}$. Spectral absorption index was measured 20 times higher for the range of $900 \mathrm{~nm}-1150 \mathrm{~nm}$ compared to the $700 \mathrm{~nm}-900 \mathrm{~nm}$ [37-40]. Research studies have shown that absorption by hemoglobin is strongly spectral dependent due to a maximum absorption for NIR in $600 \mathrm{~nm}$. Measurements confirmed the decreasing tendency of the spectral absorption of

\section{References}

1 Leon G (1981) The biomedical laser, technology and clinical applications. Springer-Verlag, New York, USA.

2 Duarte FJ (2016) Tunable laser applications. (3rd edn). Optical Science and Engineering, CRC Press, Taylor \& Francis Group, UK.
Table 1 Absorption index for oxyhemoglobin and deoxyhemoglobin for specifics wavelengths.

\begin{tabular}{|c|c|c|}
\hline Wavelength $[\mathrm{nm}]$ & OxyHGb $\left[\mathrm{cm}^{-1}\right]$ & DeoxyHGb $\left[\mathrm{cm}^{-1}\right]$ \\
\hline 650 & 0.5 & 3.74 \\
\hline 700 & 1.79 & 0.42 \\
\hline 750 & 1.57 & 0.6 \\
\hline 810 & 0.92 & 0.79 \\
\hline 850 & 1.11 & 0.78 \\
\hline 900 & 1.24 & 0.88 \\
\hline 980 & 1.18 & 0.49 \\
\hline 1000 & 1.1 & 0.26 \\
\hline 1050 & 0.88 & 0.12 \\
\hline 1064 & 0.84 & 0.08 \\
\hline
\end{tabular}

Table 2 The amount of relative energy delivered to different depths of penetration.

\begin{tabular}{|c|c|c|c|}
\hline Parameters & \multicolumn{3}{c}{$\begin{array}{c}\text { The amount of relative energy delivered to } \\
\text { different depths of penetration }\end{array}$} \\
\hline Wavelength & $0.25 \mathrm{~mm}$ & $2.35 \mathrm{~mm}$ & $6.17 \mathrm{~mm}$ \\
\hline $810 \mathrm{~nm}$ & $79.21 \% \pm 0.58 \%$ & $51.49 \% \pm 0.58 \%$ & $25.74 \% \pm 1.00 \%$ \\
\hline $810 \mathrm{~nm}+970 \mathrm{~nm}$ & $88.45 \% \pm 1.00 \%$ & $64.94 \% \pm 1.53 \%$ & $36.65 \% \pm 1.53 \%$ \\
\hline $1064 \mathrm{~nm}$ & $89.24 \% \pm 1.00 \%$ & $71.71 \% \pm 0.58 \%$ & $47.41 \% \pm 1.53 \%$ \\
\hline
\end{tabular}

deoxy hemoglobin from $3.74 \mathrm{~cm}^{-1}(650 \mathrm{~nm})$ to $0.08 \mathrm{~cm}^{-1}$ for 1064 $\mathrm{nm}$ [41].

Experimental part of this study measured the relative absorption and calculated the maximal achievable penetration depth. Measured values confirmed the phenomena of increased penetration depth for the wavelength of $1064 \mathrm{~nm}$. Maximal penetration depth was calculated to $8.1 \mathrm{~cm}$ which reach a minimum $0.001 \%$ of the energy which is almost two times deeper than $4.8 \mathrm{~cm}$ for the $810 \mathrm{~nm}$ wavelength. Minimum difference was measured in the sample of thickness $0.25 \mathrm{~mm}$.

\section{Conclusion}

For laser light on the wavelength of $1064 \mathrm{~nm}$, reflection is negligible. Refraction index is three times lower for $1064 \mathrm{~nm}$ $\left(1.5 \mathrm{~cm}^{-1}\right)$ compared to the $810 \mathrm{~nm}\left(4.6 \mathrm{~cm}^{-1}\right)$. This allows for a higher amount of energy to be delivered into the tissue. Melanin absorption coefficient decreases from $690 \mathrm{~nm}\left(228 \mathrm{~cm}^{-1}\right)$ to 1064 $\mathrm{nm}\left(55 \mathrm{~cm}^{-1}\right)$ and reduces the energy loss in the skin. Decreasing absorption index of the hemoglobin from $3.74 \mathrm{~cm}^{-1}(650 \mathrm{~nm})$ to $0.08 \mathrm{~cm}^{-1}$ for $1064 \mathrm{~nm}$ presents a strong spectral dependency. Spectral dependency of the water absorption was confirmed and measured 20 times higher in the range of $900 \mathrm{~nm}-1150 \mathrm{~nm}$ compared to $700 \mathrm{~nm}-900 \mathrm{~nm}$. Experimental analysis confirmed the deeper penetration of the $1064 \mathrm{~nm}$ wavelength compared to the $810 \mathrm{~nm}$ and $970 \mathrm{~nm}$.

3 Takac S, Stojanović S, Muhi B (1998) Excision of oral leukoplakia by $\mathrm{CO}_{2}$ lasers versus traditional scalpel: A comparative study. Med Pregl 51: $146-150$

4 Pratesi R (2012) Optronic techniques in diagnostic and therapeutic medicine. Springer Science \& Business Media. 
5 Leal J, Pinto EC, Lopes RAB, Dalan F (2008) Effect of 655-nm low-leve laser therapy on exercise-induced skeletal muscle fatigue in humans. Photomedicine and Laser Surgery 26: 419-424.

6 Leal J, Pinto EC, Lopes RAB, Vanin AA, Baroni BM, et al. (2009) Effect of $830 \mathrm{~nm}$ low-level laser therapy in exercise-induced skeletal muscle fatigue in humans. Lasers Med Sci 24: 425-431.

7 Ali G, Aysegul S, Remzi C, Ozlem A (2004) Efficacy of $904 \mathrm{~nm}$ gallium arsenide low level laser therapy in the management of chronic myofascial pain in the neck: A double-blind and randomize-controlled trial. Lasers Surg Med 35: 229-235.

8 Capp PR, Bjordal JM, Frigo L (2012) Infrared (810 nm) low-level laser therapy on rat experimental knee inflammation. Lasers Med Sci 27 71-78.

9 Cleber F, Taysa DBO, Leonardo DOZ, Rodrigo BDMR, Vilmar B, et al. (2011) Effects of low level laser therapy ( $808 \mathrm{~nm}$ ) on physical strength training in humans. Lasers Med Sci 26: 349-358.

10 Leal J, Pinto EC, Lopes RAB, Bruno MB (2009) Effect of $830 \mathrm{~nm}$ lowlevel laser therapy applied before high-intensity exercises on skeletal muscle recovery in athletes. Lasers Med Sci 24: 857-863.

11 Rungsima W, Kanchalit T, Sumanas B (2015) Efficacy and safety of 1064-nm Nd: YAG laser in treatment of onychomycosis. J Dermatol Treatm 27: 75-79.

12 Aslihan U, Beyhan C, Serdar O, Tuncer D, Mutan H (2014) Effects of laser irradiation at different wavelengths $(660,810,980$, and 1,064 $\mathrm{nm}$ ) on mucositis in an animal model of wound healing. Lasers Med Sci 29: 1807-1813.

13 Afrina M (2018) Agarose-based tissue mimicking optical phantoms for diffuse reflectance spectroscopy. J Visualiz Exp 138: e57578.

14 Tom L, Philip AW, Paul HC (2012) Optical properties of human skin. J Biomed Optics 17: 1-2.

15 The LibreTexts libraries (2018) The LibreTexts libraries Dostupnéz. Libertexts, California, USA.

16 Bashkatov AN, Genina EA, Kochubey VI (2005) Optical properties of human skin, subcutaneous and mucous tissues in the wavelength range from 400 to $2000 \mathrm{~nm}$. J Appl Phys 38: 2543-2555.

17 Elli A (1999) The reflectance spectrum of human skin. Technical report. University of Pennsylvania, USA.

18 Norvang LT, Milner TE, Nelson JS, Berns MW (1997) Skin pigmentation characterized by visible reflectance measurements. Lasers Med Sci 12: 99-112.

19 Anderson RR, Parrish JA (1981) The optics of human skin. J Investig Dermatol 77: 13-19.

20 Alfred V, Christian D, Roland N, Reginald B (1991) Optical properties of human sclera, and their consequences for transscleral laser applications. Lasers Surg Med 11: 331-340.

21 Judith RM, James PF, Andreas HH, Angelia AE, Dan S, et al. (1998) Mechanisms of light scattering from biological cells relevant to noninvasive optical-tissue diagnostics. Appl Optics 37: 2-4.

22 Philip M, Herman F (1999) Methods of theoretical physics. McGrawHill, Boston, USA.

23 Elena S, Brian J, John N, Anna NY (2006) Optical properties of normal and cancerous human skin in the visible and near-infrared spectral range. J Biomed Optics 11: 2-4.

24 Troy R, Tamara L, Suresh NA (2001) Thennadil: Optical properties of human skin in the near infrared wavelength range of 1000 to 2200 $\mathrm{nm}$. Journal of Biomedical Optics 6(2): 1-9.

25 Chan EK, Sorg B, Protsenko D, Neil MO, Motamedi M (1991) Effects of compression on soft tissue optical properties. IEEE J Selec Topics Quant Electr 2: 943-950.

26 Amin MJ (2010) Overview of radiation therapy terms and procedures in the management of thoracic malignancies. Med Manag Thorac Surg Patient 3: 252-262.

27 Krystyna S, Anna DL, Slawomir K, Irena T (2009) Melanin from epidermal human melanocytes: Study by pyrolytic GC/MS. J Am Soc Mass Spectr 20: 464-468.

28 Uddhav PA, Lakshyajit DD (2008) Overview of lasers. Indian J Plastic Surg 44: 101-113.

29 Aravind K, Baranoski GVR (1990) A biophysically-based spectral model of light interaction with human skin. Eurographics 23 : 331-340.

30 Jennifer R (2007) The spectroscopic properties of melanin. Thesis. University of Queensland, Australia.

31 Lihong WV, Hsin WU. Biomedical optics: Principles and imaging, Wiley-Interscience, Hoboken, New Jersey, USA.

32 Steven JL, Steven LJ, Randolph D, Schwartz JA (1996) Internal absorption coefficient and threshold for pulsed laser disruption of melanosomes isolated from retinal pigment epithelium. Photochem Photobiol Pergamon Press 5: 468.

33 Jacques NL, Mcauliffe DJ (1991) The melanosome: Threshold temperature for explosive vaporization and internal absorption coefficient during pulsed laser irradiation. Photochem Photobiol Pergamon Press 53: 769-775.

34 Henry G, Carmine DC (1979) Anatomy of the human body. (30th edn). Lea and Febiger, Philadelphia, USA.

35 Irvine M, Pollack WJB (1968) Infrared optical properties of water and ice spheres. Icarus 8: 324-360

36 George HM, Marvin RQ (1973) Optical Constants of Water in the 200 $\mathrm{nm}$ to $200 \mu \mathrm{m}$ wavelength Region. Appl Optics 12: 1-2.

37 Kent $\mathrm{P}$ (1974) Optical properties of water in the near infrared. J Opt Soc America 64: 1-2.

38 Takatani G (1979) Theoretical analysis of diffuse reflectance from a two-layer tissue model. IEEE Trans Biomed Eng 26: 656-664.

39 Tseng HT, Paulo B, Anthony D (2009) Chromophore concentrations, absorption and scattering properties of human skin in vivo. Opt Express 17: 14599-14617.

40 Susan W, Mark C, David TD, John SW, Osmund RR (1988) Characterization of the near infrared absorption spectra of cytochrome aa3 and haemoglobin for the non-invasive monitoring of cerebral oxygenation. Biochim Biophys Acta 933: 184-192.

41 Steven L (2013) Optical properties of biological tissues: A review. Phys Med Biol 58: R37-R61. 